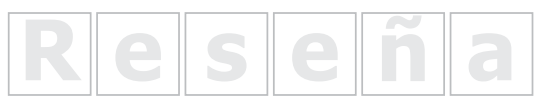





\section{Protección social y lucha contra la pobreza en Brasil, Colombia y Chile: ¿graduarse de los PTC o salir de la pobreza?}

\section{Carlo Tassara (editor), Antonio Ibarra y Luis Hernán Vargas Faulbaum, Programa EUROsociAL, en colaboración con el Instituto Ítalo-Latinoamericano (IILA) y el Comitato Internazionale per lo Sviluppo dei Popoli, Madrid, 2015.}

ISBN: 978-88-99592-00-4. 212 páginas.

Fabio Sánchez Cabarcas*

Disponible en línea: 30 de junio de 2016 Bogotá, 07/02/2016

doi:10.11144/Javeriana.papo21-1.pslc

\section{Cómo citar esta reseña:}

Sánchez Cabarcas, F. (2016). Reseña del libro Protección social y lucha contra la pobreza en Brasil, Colombia y Chile: ¿graduarse de los PTC o salir de la pobreza? Carlo Tassara (editor), Antonio Ibarra y Luis Hernán Vargas Faulbaum. Papel Político, 21(1), 287-292. http:// dx.doi.org/10.11144/Javeriana.papo21-1.pslc

El trabajo elaborado por Carlo Tassara ${ }^{1}$ (editor), Antonio Ibarra y Luis Hernán Vargas Faulbaum constituye una obra novedosa y pertinente para el público interesado en comprender y analizar la eficacia de los programas de protección social en América Latina. La obra parte con un interesante cuestionamiento: ¿cómo aumentar la eficacia de los Programas de Transferencias Condicionadas (PTC) en la lucha contra la pobreza, para garantizar a la población una salida de la marginalidad y la exclusión social? Al respecto, los autores también se cuestionan sobre las dificultades de articular los PTC con políticas

\footnotetext{
${ }_{1}^{1}$ Profesor de la Universidad de Roma La Sapienza. Tassara dicta clase de posgrado en ciencias políticas, relaciones internacionales y cooperación para el desarrollo en la Universidad Externado de Colombia, la Universidad de los Andes, la Pontificia Universidad Javeriana y otros prestigiosos claustros colombianos. Es también experto de políticas públicas del Consejo Internacional de Seguridad y Protección. Página web: https://uniroma1.academia. edu/CarloTassara
}

\footnotetext{
* Director de Investigación, Escuela de Política y Relaciones Internacionales Universidad Sergio Arboleda, Bogotá. fabio.sanchez@usa.edu.co
} 
de Estado a mediano y largo plazo, sin que dependan de los giros políticos tan comunes en América Latina y, además, son críticos con los periodos máximos de permanencia en los PTC, cuando la evidencia señala que salir de la pobreza no se puede medir en pocos años y que las personas necesitan acompañamiento para no recaer en dicha situación.

La superación de la pobreza en América Latina es un tema que atraviesa el debate político y académico desde hace varias décadas, y esta obra constituye un referente para su estudio, dado su soporte empírico y nivel de análisis. Lo consignado es producto del "Estudio regional sobre reglas de graduación y estrategias de egreso de los beneficiarios de los PTC", a cargo del Comitato Internazionale per lo Sviluppo dei Popoli y dirigido por el editor del libro. Este estudio fue realizado en paralelo a la "Investigación sobre inclusión productiva de los beneficiarios del PTC”, a cargo de la División de Desarrollo Social de la Comisión Económica para América Latina y el Caribe. Lo anterior dentro del Programa EUROsociAL de la Unión Europea y, en particular, del Área de Políticas Sociales, coordinado por el Instituto Ítalo-Latinoamericano.

La organización de la obra ${ }^{2 *}$ es uno de sus puntos fuertes, dada su utilidad como material de consulta para académicos y el público en general. En el primer capítulo, se encuentra un análisis histórico de las diversas estrategias que se han aplicado en la lucha contra la pobreza en América Latina, los objetivos e impactos de los PTC. Los tres capítulos siguientes contienen los estudios de caso de Brasil, Colombia y Chile, respectivamente. Finalmente, el último capítulo contiene una valoración de la evidencia empírica hallada, que nos lleva a cuestionarnos sobre las dificultades que aún persisten para reducir la desigualdad y superar la pobreza en América Latina.

En este marco, el primer capítulo del libro presenta un análisis completo sobre la situación económica y social de América Latina. Una región que ha mejorado su perfil económico y comercial, pero en la que persiste una alta desigualdad en el nivel del ingreso, limitada efectividad en las políticas públicas de inclusión social, insuficiente calidad en los servicios de salud y educación, centralismo político, escaso avance en las políticas fiscales y pobre infraestructura. Este panorama nos lleva a unas cifras alarmantes: de acuerdo con el coeficiente de Gini, América Latina y el Caribe presentan la desigualdad más alta y persistente, lo cual se traduce en una pobreza cercana a $28 \%$ de la población y una indigencia en $12 \%$, lo que arroja 167 millones de pobres y 71 millones de indigentes.

Este complejo panorama se presenta en medio de un cambio de tendencias políticas en la región, un giro hacia Gobiernos de izquierda y centroizquierda, que desde la primera década del siglo XXI favorecieron la implementación de políticas sociales. Es en este contexto que los PTC se conciben para detener la continuidad de la pobreza entre generaciones y

\footnotetext{
${ }^{2}$ El libro es una edición no venal, está libremente disponible para la consulta y se puede descargar en el siguiente enlace https://www.academia.edu/16840419/Protecci\%C3\%B3n_social_y_lucha_contra_la_pobreza_en_Brasil_Colombia_y_Chile._Graduarse_de_los_PTC_o_salir_de_la_pobreza
} 
promover el desarrollo en los sectores más vulnerables. Al respecto, los autores identifican las bondades de estos programas: van más allá del esquema tradicional de los seguros sociales y establecen la corresponsabilidad de los beneficiarios para mejorar los niveles de educación, salud y alimentación, todo esto aumentando el capital humano.

Los PTC irrumpen en el escenario social en la década de 1990, y son pioneros en Brasil (1995), México (1997) y Ecuador (1998). Ya para 2013, según la Comisión Económica para América Latina y el Caribe , operaban en 21 países y cubrían más de 30 millones de familias. Los programas más conocidos son Bolsa Familia de Brasil y Progresa (definido Oportunidades entre 2001 y 2014) en México. El estudio destaca la capacidad de estos programas de sacar de la pobreza a millones de latinoamericanos, a pesar de que no han servido para encarar algunos temas de fondo, como una reforma sustantiva del mercado laboral, la redistribución equitativa del ingreso y la creación de sistemas de protección social más incluyentes.

Con relación a la medición del impacto de los PTC, los autores señalan dos métodos: evaluaciones experimentales y cuasiexperimentales, a las que también han acompañado metodologías cualitativas. Ha sido evidente un efecto positivo donde se presenta una amplia cobertura y el monto de las transferencias es más alto, pero donde se cuenta con menos recursos, por lo que los resultados han sido ínfimos. Esta lógica, que resulta simple, esconde un complejo universo de variables sociales, culturales y económicas que, en los estudios de caso, se identifican y analizan con rigurosidad.

El segundo capítulo estudia las estrategias que han adoptado en Brasil para superar la pobreza. Encontramos un punto de partida interesante con el programa Hambre Cero, que inició durante el mandato del presidente Lula da Silva en 2003, el cual preparó el camino para el famoso Bolsa Familia en 2004, que para 2014 beneficiaba a 14 millones de familias. Estos programas han sido posibles gracias a una planeación integral, que incluyó una amplia capacitación de los funcionarios públicos a través de la Escuela Nacional de Administración Pública. Asimismo, se elaboró un Catastro Único para Programas Sociales, que complementó a los Centros de Referencia de la Asistencia Social, los Centros de Referencia Especializados de la Asistencia Social, las Unidades Básicas de Salud y las importantes guarderías para niños.

Lo anterior es solo una muestra de la compleja red de instrumentos con los que Brasil ha logrado mejorar las condiciones de salud, educación, el mercado de trabajo y la agricultura familiar. También ha promovido el microempresariado familiar y la economía solidaria, aspectos con los que ha logrado sacar de la pobreza a más de 28 millones de personas y crear una clase media de 36 millones. No obstante, existen problemas y debilidades, por ejemplo, los autores explican cómo los resultados de los programas son altamente variables entre las zonas rurales y urbanas y es persistente una alta rotación de la mano de obra con bajos salarios. 
En el tercer capítulo se analiza a Colombia. Se trata de un caso especial, ya que el conflicto interno del país ha empobrecido a grandes sectores urbanos y rurales del país, lo cual ha complicado la respuesta ante las necesidades sociales. Al igual que en el capítulo anterior, los autores analizan los antecedentes y elaboran un contexto de referencia. Tienen como punto de partida la Constitución Política de 1991, con la que se estableció la seguridad social como una obligación del Estado. Ello llevó a varios cambios que se identificaron a través del Consejo Nacional de Política Económica y Social, que sentó los criterios de focalización del gasto público. Asimismo, se creó la controvertida Ley 100 de 1993, con la que nació el sistema de seguridad social integral y sus dos principales componentes: el Sistema General de Seguridad Social en Salud y el Sistema General de Pensiones, a lo que se unió en 1994 la Ley 115, que introdujo el derecho universal de la educación y el Sistema de Selección e Identificación de Beneficiarios de Programas Sociales. Estas medidas crearon redes de protección para los más necesitados, y así el gasto social pasó de 6 \% en 1990 a 14.5 \% en 1996; no obstante, la recesión económica originada en Asia afectó la economía, y la recuperación tardó casi diez años, para en 2010 llegar a 13.6 \% en gasto social.

En este capítulo, los autores también hacen un estudio cronológico de las diversas estrategias que Colombia ha adoptado para superar la pobreza: Sistema Nacional de Atención Integral a Población Desplazada en 1997, Red de Apoyo Social en 2000, Acción Social en 2005, Plan Nacional de Desarrollo 2010-2014 "Prosperidad para todos", hasta llegar al nuevo Plan Nacional de Desarrollo 2014-2018 “Todos por un nuevo país: paz, equidad, educación”, con el cual la Administración de Juan Manuel Santos busca mejorar las condiciones para un posconflicto que está ad portas, si se concretan los actuales diálogos de paz que se adelantan en La Habana desde 2012 con las Fuerzas Armadas Revolucionarias de Colombia. Asimismo, señalan los autores que para el caso colombiano la promoción social ha sido el eje sobre el cual se articulan los PTC, y las entidades más involucradas en dicha labor son el Departamento para la Prosperidad Social y la Agencia Nacional para la Superación de la Pobreza Extrema, ambas creadas en 2011. En la parte final, analizan las reglas de graduación del programa Más Familias en Acción y de la Red Unidos, tras lo cual encuentran una evidencia importante sobre las dificultades que se interponen para salir de la pobreza.

El capítulo siguiente analiza el caso chileno, donde se cambió de un enfoque guiado de necesidades básicas hacia uno universalista. Durante la dictadura (1973-1990) el asunto de la pobreza fue estudiado según el análisis de la población de bajos ingresos, un punto de partida es la Encuesta de Presupuestos Familiares de 1987. Posteriormente, el eje de la política pública en la reducción de la pobreza se basó en las transferencias monetarias focalizadas, cuyos hitos son la introducción del Subsidio Único Familiar, las Pensiones Asistenciales y las asignaciones familiares para asalariados pobres, y con el fin de implementar estas transferencias se crea la ficha CAS, que tiene sus orígenes 
en los Comités de Asistencia Social. Ya en 1990, con la recuperación de la democracia, se desveló un nivel de pobreza de $38.4 \%$, déficit en viviendas y una baja cobertura en salud y educación. Para atender el asunto de las viviendas, Chile ha desarrollado un sistema de subsidios, exigiendo un ahorro mínimo o la posesión de un crédito hipotecario.

Asimismo, se dio prioridad a un plan para mejorar el funcionamiento de la red de salud pública. Paradójicamente, la estrategia para la educación elaborada durante la dictadura se mantuvo en los posteriores Gobiernos democráticos, ya entre 1990 y 1995 aumentó la inversión y se implementó una reforma educacional.

En cuanto a la lucha contra la pobreza, se mantuvo la lógica basada en las transferencias monetarias focalizadas, y la creación del Fondo de Solidaridad e Inversión Social. Este permitió introducir componentes orientados a la generación de capacidades y actividades de promoción y desarrollo social. Posteriormente, el enfoque basado en la garantía de derechos se presenta durante la Administración de Ricardo Lagos (20002006) cuando se lanza un nuevo seguro de desempleo y el programa Chile Solidario, que utilizó la infraestructura jurídica e institucional del programa Puente. En 2004, se reformó la salud a través del Plan Atención Universal de Garantías Explícitas. Posteriormente, durante el primer mandato de Michelle Bachelet (2006-2010), se creó Chile Crece Contigo, con el cual se buscó extender la cobertura de educación preescolar. En 2012, se puso en acción el programa Ingreso Ético Familiar con un elevado presupuesto y, en 2014, se calculó la pobreza monetaria con una nueva metodología.

Tal y como hemos visto, el trabajo contiene un análisis robusto de las estrategias que los países seleccionados han utilizado para reducir los niveles de pobreza. Simplemente he destacado aspectos que son de interés para quienes desean conocer las dificultades que aún enfrenta una América Latina en desarrollo. En las conclusiones de la obra, los autores señalan cómo, de forma errónea, en los PTC se ha hecho mayor énfasis en las reglas para graduarse de los programas que en las estrategias de salida de la pobreza, lo cual nos lleva a la siguiente alerta: la reducción de la pobreza no es igual a la reducción de la vulnerabilidad, que concuerda con las actuales cifras de marginalidad social que crecen o se mantienen en diversas regiones urbanas y rurales de América Latina.

Se trata de una obra obligada para quienes estudian las políticas púbicas de lucha contra la pobreza en América Latina y sus interrelaciones con la agenda de gobernanza mundial del desarrollo, que se ha ido consolidando en el ámbito internacional desde que fue planteada, en 2008, en el G20 y desde la creación de la Alianza de Busan para una cooperación eficaz al desarrollo en 2011.

Finalmente, el trabajo nos ilustra con evidencia empírica y nos advierte sobre la grave vulnerabilidad que un alto porcentaje de la población tiene en la región, y que es susceptible de marginalizarse nuevamente. Estos sectores pobres tienen expectativas en cuanto a la mejora de los servicios de salud, educación y empleo, y para ello es necesaria 
la consolidación de políticas de Estado a largo plazo con sistemas de protección social sólidos y efectivos. Lo mejor que le puede pasar a este trabajo es caer en manos de los decisores políticos, que pueden evitar la continuidad del drama de millones de ciudadanos latinoamericanos y caribeños. 